\title{
PERAN PRODUK WISATA DAN CITRA DESTINASI TERHADAP KEPUTUSAN BERKUNJUNG WISATAWAN
}

\author{
Indri Safitri \\ Universitas Muhammadiyah Sukabumi \\ indrisafitri@ummi.ac.id \\ Asep M. Ramdan \\ Universitas Muhammadiyah Sukabumi \\ amr37ramdan@ummi.ac.id \\ Erry Sunarya \\ Universitas Muhammadiyah Sukabumi \\ errysoen@ummi.ac.id
}

Abstract

The purpose of this study is to determine the role of tourism products and destination image of tourists visiting decision. The method in this study uses a type of probability sampling, including simple random sampling with a sample of 200 respondents. The analysis technique used is multiple linier regression analysis, coefficient of determination, simultaneous model testing ( $F$ test), and partial hypothesis testing ( $T$ test). T test result shower that tourism products had a positive and significant effect on visiting decisions, destination image had a positive and significant effect on visiting decisions. The F test results the probability value sig. 0,000<0,05 which means that the F test can be accepted and shows the influence simultaneously. Based on the results of the coefficient of determination test obtained a value of 0,596 can be interpreted that the influence of tourism products and destination image on the decision of visiting that is equal to 59,6\%, the remaining 40,4\% is influenced by other factors not explained this study.

Keywords : destination image; tourism product; visiting decision.

\section{PENDAHULUAN}

Wisata dewasa ini menjadi sebuah pilihan yang tepat bagi individu maupun kelompok dengan tujuan untuk berlibur atau rekreasi dengan melakukan perjalanan dari satu tempat ketempat lain dalam memperoleh kesenangan dan kepuasan. Pariwisata menjadi salah satu industri yang paling menguntungkan bagi beberapa negara karena telah meningkatkan pendapatan devisa dan memberikan dorongan untuk pembangunan kesejahteraan ekonomi masyarakat (Phau, Quintal, \& Shanka, 2014).

World Of Tourism Organization mengungkapkan bahwa industi pariwisata memperlihatkan pertumbuhan yang konsisten dari tahun ke tahun dan diperkirakan akan terjadi peningkatan terhadap angka kunjungan wisatawan dunia. Dalam hal ini indonesia dapat menjadi salah satu negara dengan potensi industri pariwisata yang prospektif, potensi yang dimiliki seperti potensi wisata alam, potensi kebudayaan, dan potensi manusia (Sari, 2015).

Pengelolaan potensi wisata dengan baik akan berimplikasi positif dengan keputusan berkunjung. Keputusan untuk melakukan perjalanan wisata pada dasarnya sama dengan keputusan pembelian, keputusan berkunjung dalam memilih serta mengevaluasi dua atau lebih alternatif yang ada (Mardiyani \& Murwatiningsih, 2015) untuk menyelesaikan masalah dapat dilihat bagaimana wisatawan menjadikan daya tarik wisata dan merek sebagai bahan pertimbangan yang kuat, hal lain yang dapat mempengaruhi keputusan dilihat dari lokasi yang strategis dan tidak membutuhkan banyak waktu, tinggi/ rendahya tarif yang ditentukan tentunya akan memberikan imbas dan timbal balik pada wisatawan serta adanya fasilitas yang lengkap dan kenyamanan pada pelayanan yang diberikan harus mampu menimbulkan kepuasan sehingga akan mengakibatkan seberapa sering wisatawan melakukan kunjungan dalam waktu berbeda (Dewi, 2018). 
Keputusan berkunjung pada suatu destinasi wisata pada umumnya wisatawan merencakanan jauh hari sebelumnya karena produk wisata dapat dirasakan apabila wisatawan mengunjungi daerah tujuan wisata secara langsung karena produk wisata itu sendiri tidak dapat dicoba atau dicicipi terlebih dahulu bahkan perjalanan panjang pada saat meninggalkan tempat tinggalnya sampai pada daerah tujuan wisata dan kembali ketempat asalnya dimana ia berangkat semula dianggap sebagai produk wisata yang dibeli (Valentino, 2019).

Seorang wisatawan sebelum membuat suatu keputusan untuk melakukan kunjungan melihat bagaimana bagus atau tidaknya citra destinasi pada suatu objek wisata yang tertanam dalam pikiran seseorang, citra destinasi dalam benak wisatawan tidak selamanya selaras dengan kondisi nyata yang ada pada destinasi itu sendiri dan juga penilaian yang diberikan wisatawan berbeda antara satu individu dengan yang lainnya (Setyaningsih \& Murwatiningsih, 2017), maka pada suatu objek wisata dalam menyediakan pengalaman sesuai dengan kebutuhan, sehingga akan membuat citra destinasi mudah dikenal dan selalu diingat oleh wisatawan sebagai citra yang baik suatu objek wisata yang dipilih (Rahayu \& Hendro, 2015).

Suatu objek wisata dapat dikatakan berhasil apabila dapat memberikan jasa atau pengalaman sesuai dengan harapan wisatawan dengan demikian diperkirakan dapat meningkatkan jumlah kunjungan wisatawan ke objek wisata (Surgawi, 2016) akan tetapi, dengan adanya penurunan atau ketidakstabilan jumlah wisatawan yang berkunjung diakibatkan terdapat banyaknya pesaing potensi objek wisata sehingga wisatawan lebih memilih berkunjung ke objek wisata yang lebih menarik untuk dikunjungi (Illah, Sularso, \& Irawan, 2019; Priyanto, Widiartono, \& Listyorini, 2016; Safitasari \& Maftukhah, 2017).

Penelitian ini bertujuan untuk mengetahui bagaimana produk wisata, citra destinasi dapat mempengaruhi keputusan berkunjung wisatawan. Adapun tujuan dalam penelitian ini yaitu untuk mengukur peran produk wisata dan citra destinasi terhadap keputusan berkunjung wisatawan.

\section{KAJIAN PUSTAKA DAN PENGEMBANGAN HIPOTESIS}

\section{Keputusan Berkunjung}

Keputusan berkunjung pada suatu jasa atau wisata yang ditawarkan memakai konsep keputusan pembelian, hal ini didukung menurut (Arista, Darsiharjo, \& Marhanah, 2017) mengungkapkan bahwa teori yang mendasari keputusan berkunjung yaitu memakai konsep keputusan pembelian. Keputusan berkunjung merupakan hasil dimana wisatawan benar-benar memutuskan untuk mengunjungi destinasi wisata yang disukai dari berbagai macam alternatif destinasi yang ada (Kotler \& Keller, 2016; Nurhasanah, Ramdan, \& Komariah, 2019; Sudaryono, 2016).

Beragam dimensi untuk mengukur keputusan berkunjung menurut (Kotler \& Keller, 2016) terdapat enam dimensi yaitu pemilihan produk atau jasa, pemilihan merek, pemilihan penyalur, jumlah kunjungan, penentuan waktu berkunjung, dan metode pembayaran. Dimensi ini juga senada dengan yang digunakan oleh (Rizki \& Pangestuti, 2017).

Pemilihan produk atau jasa yaitu suatu daerah tujuan wisata mampu memusatkan perhatian kepada orang-orang yang berminat untuk mengunjungi, serta memperkuat daya tarik wisata sehingga wisatawan dapat mengambil keputusan untuk mengunjungi daerah tujuan wisata sebagai pemilihan produk atau jasa (Dharmmesta \& Handoko, 2012; Mulyani, 2018). Pemilihan merek yaitu pada setiap merek mempunyai perbedaan tersendiri yang dapat mempengaruhi wisatawan dalam pengambilan keputusan (Dharmmesta \& Handoko, 2012; Mulyani, 2018). Pemilihan penyalur yaitu pada setiap keputusan wisatawan akan berbeda-beda karena berbagai faktor seperti lokasi yang dekat, harga yang murah, kenyamanan melakukan pembelian dan lain sebagainya (Dharmmesta \& Handoko, 2012; Mulyani, 2018). Jumlah kunjungan bagi wisatawan dalam pengambilan keputusan tentang seberapa sering produk yang akan dikunjungi, sehingga akan berdampak pada frekuensi tingkat kunjungan (Dharmmesta \& Handoko, 2012; Mulyani, 2018). Penentuan waktu berkunjung yaitu suatu keputusan 
Indri Safitri, Asep M. Ramdan, \& Erry Sunarya. Peran Produk Wisata dan Citra Destinasi terhadap Keputusan Berkunjung Wisatawan

akan berkunjung dibuat dalam pilihan waktu dapat berbeda-beda sesuai dengan kapan produk tersebut dibutuhkan (Dharmmesta \& Handoko, 2012; Mulyani, 2018).

\section{Produk Wisata}

Produk dalam industri pariwisata merupakan suatu produk yang disebut dengan produk line dalam arti bahwa penggunaannya dilakukan pada waktu bersamaan (Yoeti, 2013). Produk wisata merupakan keseluruhan fasilitas atau pelayanan yang berbentuk nyata atau tidak nyata disediakan bagi wisatawan yang diperoleh dan dirasakan atau dinikmati agar suatu kesatuan rangkaian perjalanan dapat memberikan pengalaman yang baik bagi wisatawan semenjak seninggalkan tempat tinggalnya sampai ke daerah tujuan wisata yang dipilih hingga kembali ketempat asalnya (Muljadi, 2009; Octaviany, 2016).

Adapun dimensi produk wisata sebagai alat ukur menurut Muljadi (2012), yaitu atraksi wisata, fasilitas dan amenitas, serta aksebilitas. Dimensi ini juga senada dengan yang digunakan oleh Dani \& Thamrin, (2019). Penelitian ini menggunakan dimensi sebagai berikut. (1) Atraksi wisata, merupakan potensi yang dimiliki yang dapat menarik wisatawan untuk berkunjung. (2) Fasilitas dan amenitas, yaitu berbagai fasilitas yang dapat menunjang satu dengan yang lain yang dapat memberikan kenyamanan serta kepuasan bagi para wisatawan selama melakukan perjalanan wisata. (3) Aksebilitas, yaitu kemudahan seorang wisatawan untuk mencapai daerah tujuan wisata melalui media transportasi (Dani \& Thamrin, 2019; Muljadi, 2012).

Faktor yang menjadi dasar pengambilan keputusan berkunjung adalah produk wisata maka dari itu salah satu fungsi produk wisata yaitu sebagai referensi wisatawan dalam setiap melakukan kunjungan ke suatu objek wisata (Huda, Rachma, \& Hufron, 2019). Elmas (2019) menyatakan adanya hubungan yang positif dan signifikan antar produk wisata terhadap keputusan berkunjung (Ramadhan \& Susanta, 2016). Artinya, semakin tinggi produk wisata maka akan semakin tinggi juga keputusan berkunjung seorang wisatawan dalam mengunjungi suatu objek wisata.

H1: Produk wisata berpengaruh positif dan signifikan terhadap keputusan berkunjung.

\section{Citra Destinasi}

Citra pada suatu destinasi wisata dikenal degan istilah destination image (citra destinasi), sehingga citra destinasi dapat diartikan sebagai keyakinan, kesan dan pikiran emosional individu maupun kelompok terhadap tempat wisata tertentu (Loi, So, Lo, \& Fong, 2017; Lopes, 2011) yang tercermin dan tersimpan dalam ingatan wisatawan $(\mathrm{Wu}, \mathrm{Li}, \& \mathrm{Li}, 2018)$, terbentuknya citra destinasi yaitu dari gabungan berbagai faktor yang ada pada destinasi seperti cuaca, pemandangan alam, keamanan, keramah-tamahan dan lain sebagainya (Coban, 2012).

Al-Kwifi (2015) menyatakan bahwa terdapat dua dimensi untuk mengukur citra destinasi, yaitu sebagai berikut. (1) Citra destinasi kognitif, yaitu penilaian rasional (pemikiran) yang menjelaskan keyakinan dan informasi yang dimiliki seseorang tentang suatu destinasi wisata (Ayuningtyas, Fauzi, \& Nuralam, 2019; Qu, Kim, \& Im, 2011), (2) Citra destinasni afektif, adalah gambaran emosi atau perasaan wisatawan mengenai suatu destinasi wisata (Ayuningtyas et al., 2019; Qu et al., 2011).

Citra yaitu seperangkat keyakinan, ide, serta tayangan seseorang mengenai objek wisata (Kotler, 2009). Ketika seorang wisatawan akan membuat suatu keputusan maka citra adalah kenyataan yang diandalkan dalam mengunjungi suatu objek wisata, karena wisatawan cenderung memilih produk terkenal atau yang telah digunakan oleh banyak orang dibandingkan mengunjungi suatu objek wisata yang mereka tidak tahu sebelumnya (Rahayu \& Hendro, 2015), sikap serta tindakan wisatawan terhadap suatu objek wisata sangat dipengaruhi oleh citra dari suatu objek wisata. Hai ini didukung oleh hasil penelitian yang menyatakan bahwa hubungan citra destinasi terhadap keputusan berkunjung menurut (Damarsiwi \& Wagini, 2018; Mohaidin, Wei, \& Murshid, 2017) "citra destinasi berpengaruh positif dan signifikan terhadap keputusan berkunjung".

H2: Citra destinasi berpengaruh positif dan signifikan terhadap keputusan berkunjung. 


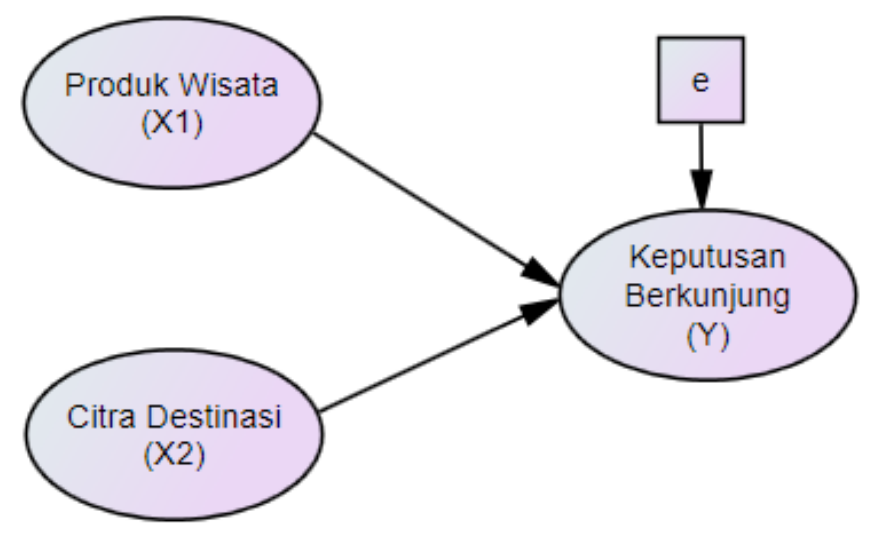

Gambar 1. MODEL PENELITIAN

\section{METODE PENELITIAN}

Metode penelitian adalah kuantitatif dengan metode asosiatif. Model penelitian dapat dilihat di Gambar 1. Penelitian ini dilakukan di Objek Wisata Pemandian Air Panas Cikundul Kota Sukabumi, merupakan objek wisata yang memiliki penawaran untuk berwisata karena keunikan sumber mata alam air panas alami dan pemandangan yang masih asri. Populasi dalam penelitian ini wisatawan yang sudah pernah berkunjung ke Objek Wisata Pemandian Air Panas Cikundul. Metode yang digunakan adalah menggunakan teknik probability sampling dengan metode pendekatan simple rendom sampling dengan jumlah sampel yang digunakan dalam penelitian ini sebanyak 200 responden. Teknik analisis data yang digunakan yaitu regresi linier berganda.

\section{HASIL DAN PEMBAHASAN}

\section{Uji Kelayakan Model}

Berdasarkan tabel 1, uji F yang dilakukan memperoleh nilai sig. 0,000 $<0,05$; serta menunjukan nilai $\mathrm{F}_{\text {hitung }} 145,226$, maka nilai $\mathrm{F}_{\text {hitung }} 145,226>\mathrm{F}_{\text {tabel }} 3$ 3,04. Artinya, adanya pengaruh simultan variabel produk wisata dan citra destinasi terhadap keputusan berkunjung.

\section{Koefisien Determinasi $\left(\mathbf{R}^{2}\right)$}

Tabel 1 menunjukkan nilai R sebesar 0,772. Artinya, ada hubungan (korelasi) yang kuat antara Produk Wisata dan Citra Destinasi sebagai variabel independen (X) dengan Keputusan Berkunjung sebagai variabel dependen (Y), dan nilai koefisien determinasi sebesar 0,592. Sedangkan nilai R Square sebesar 0,596 hal ini menunjukkan bahwa persentase sumbangan pengaruh variabel independen terhadap variabel dependen sebesar 59,6\% sedangkan sisanya 40,4\% dari faktor yang tidak diteliti.

\section{Tabel 1. HASIL UJI F \& KOEFISIEN DETERMINASI}

\begin{tabular}{lc}
\hline Keterangan & Hasil \\
\hline F hitung & 145,226 \\
Sig &, 000 \\
R &, 772 \\
R Square &, 596 \\
Adjusted R Square &, 592 \\
\hline
\end{tabular}

Sumber: Data diolah.

\section{Analisis Regresi Linier Berganda}

Hasil pengolahan regresi linier berganda dapat dilihat pada tabel 2. Tabel 2 menunjukkan bahwa kedua variabel yang terdiri dari produk wisata dan citra destinasi menunjukkan hasil yang positif dan signifikan terhadap variabel keputusan berkunjung, diperoleh nilai constanta (a) sebesar 1.496 dan nilai 
Indri Safitri, Asep M. Ramdan, \& Erry Sunarya. Peran Produk Wisata dan Citra Destinasi terhadap Keputusan Berkunjung Wisatawan

produk wisata sebesar 0,600 adapun nilai citra destinasi sebesar 1.014, sehingga dapat diperoleh persamaan (1).

$Y=\alpha+\beta_{1} X_{1}+\beta_{2} X_{2}=1.496+0,600 X_{1}+1.014 X_{2}$

\section{Uji secara Parsial (Uji t)}

Tabel 2 menunjukkan variabel produk wisata memiliki $\mathrm{T}$ hitung sebesar 5,264 dengan nilai signifikan 0,000 , hasil uji t diketahui nilai $\mathrm{T}_{\text {hitung }} 5,264>\mathrm{T}_{\text {tabe1 }} 1,97208$ dengan tingkat signifikan $0,000<0,05$. Sehingga dapat diartikan bahwa hipotesis diterima, variabel produk wisata berpengaruh secara parsial terhadap keputusan berkunjung. Variabel citra destinasi memiliki T hitung sebesar 7,391 dengan nilai signifikan 0,000, hasil uji t diketahui $\mathrm{T}_{\text {hitung }} 7,391>\mathrm{T}_{\text {tabe1 }} 1,97208$ dengan tingkat signifikan $0,000<$ 0,05. Sehingga dapat diartikan bahwa hipotesis diterima, variabel citra destinasi berpengaruh secara parsial terhadap keputusan berkunjung.

Tabel 2. HASIL UJI T

\begin{tabular}{ccccc}
\hline Variabel & Coeff & SE & T & P- Value \\
\hline Constant & 1,496 & 1,191 & 1,256 &, 211 \\
Produk wisata (X1) &, 600 &, 114 & 5,264 &, 000 \\
Citra destinasi (X2) & 1,014 &, 137 & 7,391 &, 000 \\
\hline
\end{tabular}

Sumber: Data diolah.

\section{Pengaruh Produk Wisata terhadap Keputusan Berkunjung}

Produk wisata berpengaruh positif dan signifikan terhadap keputusan berkunjung. Berpengaruh positif artinya jika variabel produk wisata mengalami peningkatan, maka akan menyebabkan peningkatan pula pada keputusan berkunjung. Berdasarkan hasil tersebut, maka hipotesis $\mathrm{H}_{1}$ diterima. Hasil tersebut sesuai dengan penelitian (Elmas, 2019) bahwa produk wisata berpengaruh secara signifikan terhadap keputusan berkunjung. Selain itu sama dengan penelitian yang dilakukan oleh (Ramadhan \& Susanta, 2016) bahwa produk wisata memiliki pengaruh dan signifikan terhadap keputusan berkunjung pada objek wisata pantai klayar.

\section{Pengaruh Citra Destinasi terhadap Keputusan Berkunjung}

Citra destinasi berpengaruh positif dan signifikan terhadap keputusan berkunjung. Berpengaruh positif artinya jika variabel citra destinasi mengalami peningkatan, maka akan menyebabkan peningkatan pula pada keputusan berkunjung. Berdasarkan hasil tersebut, maka hipotesis $\mathrm{H}_{2}$ diterima. Hal ini sesuai dengan penelitian (Damarsiwi \& Wagini, 2018) yang menyatakan bahwa citra destinasi memiliki pengaruh positif dan signifikan terhadap keputusan berkunjung wisatawan ke Pulau Tikus, selain itu sama dengan penelitian yang dilakukan oleh (Huda et al., 2019) menyatakan bahwa terdapat pengaruh positif dan signifikan pada variabel citra destinasi terhadap keputusan berkunjung wisatawan Coban Jahe.

\section{KESIMPULAN}

Berdasarkan hasil penelitian yang telah dilakukan, maka ditemukan beberapa kesimpulan bahwa adanya pengaruh variabel independent yang terdiri dari dua variabel yaitu produk wisata dan citra destinasi terhadap variabel dependent yaitu keputusan berkunjung dengan teknik yang digunakan yaitu regresi linier berganda dan hasil uji hipotesis secara parsial serta simultan menyatakan adanya hubungan positif yang signifikan antara variabel produk wisata dan citra destinasi terhadap keputusan berkunjung. Penelitian selanjutnya agar menambahkan variabel-variabel seperti word of mouth dan motivasi yang tidak diteliti dalam penelitian ini, yang juga mungkin dapat mempengaruhi keputusan berkunjung wisatawan.

\section{DAFTAR PUSTAKA}

Al-Kwifi, O. S. (2015). The impact of destination images on tourists' decision making: A technological exploratory study using fMRI. Journal of Hospitality and Tourism Technology, 6(2), 174-194. 
https://doi.org/10.1108/JHTT-06-2015-0024

Arista, I., Darsiharjo, \& Marhanah, S. (2017). Pengaruh Produk Wisata Terhadap Keputusan Berkunjung Wisatawan Di Pulau Lengkuas Belitung. Manajemen Resort Dan Leisure, 14(1).

Ayuningtyas, A. S., Fauzi, A., \& Nuralam, I. (2019). Pengaruh Terpaan Media Soaial Instagram Terhadap Keputusan Berkunjung Dengan Citra Destinasi Sebagai Variabel Mediasi ( Survei pada Pengunjung Kampung Tridi ( Tiga Dimensi ) Malang ). Jurnal Administrasi Bisnis, 68(1), 4554.

Coban, S. (2012). The effects of the image of destination on tourist satisfaction and loyalty: The case of Cappadocia. European Journal of Social Sciences, 29(2), 222-232.

Damarsiwi, E. P. M., \& Wagini. (2018). Pengaruh Electronic Worth of Mouth Dan Citra Destinasi Terhadap Keputusan Berkunjung Wisatawan Ke Pulau Tikus. Seminar Nasional Royal (SENAR), 9986(September 2018), 479-484.

Dani, Y. P., \& Thamrin. (2019). Pengaruh Atribut Produk Wisata dan Electronic Word of Mouth (EWOM) Terhadap Keputusan Bekunjung pada Kawasan Wisata Mandeh. Jurnal Kajian Manajemen Dan Wirausaha, 1(1), 283-295.

Dewi, ratna indriyani. (2018). Pengaruh E-wom, Citra Destinasi dan Fasilitas Wisata terhadap Keputusan Berkujung yang Dimediasi Oleh Respon Emosional (Universitas Lampung). https://doi.org/10.1017/CBO9781107415324.004

Dharmmesta, B. S., \& Handoko, T. T. (2012). Manajemen Pemasaran Analisis Perilaku Konsumen. Yogyakarta: BPFE.

Elmas, M. S. H. (2019). The Influence Of Green Marketing, Attribute Tourism Products, E-Wom The Visit Decision. International Journal of Social Science and Business, 3(1), 46-54. https://doi.org/10.23887/ijssb.v3i1.17254

Huda, kamal musthofa, Rachma, N., \& Hufron, M. (2019). Pengaruh Citra Destinasi,Produk Wisata dan Word of Mouth Terhadap Keputusan Berkunjung ke Wisata Coban Jahe. E- Jurnal Riset Manajemen, 8(1), 90-101.

Illah, A. N., Sularso, R. A., \& Irawan, B. (2019). Pengaruh Citra Destinasi dan E-WOM di Media Sosial Instagram serta Persepsi Konsumen Terhadap Keputusan Berkunjung ke Objek Wisata B29 di Kabupaten Lumajang. E-Journal Ekonomi Bisnis Dan Akuntansi, 6(2), 164. https://doi.org/10.19184/ejeba.v6i2.11163

Kotler, P. (2009). Manajemen Pemasaran. Jakarta: Erlangga.

Kotler, P., \& Keller, K. L. (2016). Marketing Managemen. United States of America: Courier/Kendallville.

Loi, L. T. I., So, A. S. I., Lo, I. S., \& Fong, L. H. N. (2017). Does the quality of tourist shuttles influence revisit intention through destination image and satisfaction? The case of Macao. Journal of Hospitality and Tourism Management, 32, 115-123. https://doi.org/10.1016/j.jhtm.2017.06.002

Lopes, S. D. F. (2011). Destination image: Origins, Developments and Implications. PASOS : Revista de Turismo y Patrimonio Cultural, 9(2), 305-315.

Lupiyoadi, R., \& Ikhsan, R. B. (2015). Praktikum Metode Riset Bisnis. Jakarta: Salemba Empat.

Mardiyani, Y., \& Murwatiningsih. (2015). Pengaruh Fasilitas Dan Promosi Terhadap Kepuasan Pengunjung Melalui Keputusan Berkunjung Sebagai Variabel Intervening Pada Objek Wisata Kota Semarang. Management Analysis Journal, 4(1), 65-75. https://doi.org/10.15294/maj.v4i1.7220 
Indri Safitri, Asep M. Ramdan, \& Erry Sunarya. Peran Produk Wisata dan Citra Destinasi terhadap Keputusan Berkunjung Wisatawan

Mohaidin, Z., Wei, K. tze, \& Murshid, M. (2017). Factors influencing the tourists' intention to select sustainable tourism destination: a case study of Penang, Malaysia. International Journal of Tourism Cities.

Muljadi, A. J. (2009). Kepariwisataan Dan Perjalanan. Jakarta: PT. Raja Grafindo Persada.

Muljadi, A. J. (2012). Kepariwisataan Dan Perjalanan. Jakarta: PT. Raja Grafindo Persada.

Mulyani, A. (2018). Pengaruh atraksi, Motivasi Berkunjung Dan Persepsi Harga Terhadap Keputusan Berkunjung Ke Obyek Wisata Pantai Watu Bale Di Kebumen. STIE Putra Bangsa, (1), 1-14.

Nurhasanah, S., Ramdan, A. M., \& Komariah, K. (2019). Analisis Kelompok Acuan Dan Atribut Produk Terhadap Keputusan Pembelian Konsumen Tas Eiger Pada Eiger Store Kota Sukabumi. Journal of Economic, Business and Accounting, 2(2), 315-321. https://doi.org/.1037//00332909.I26.1.78

Octaviany, V. (2016). Pengaruh Kualitas Produk Pariwisata Terhadap Keputusan Berkunjung Di Bale Seni Barli-Kota Baru Parahyangan. Tourism Scientific Journal, 1(2), 184. https://doi.org/10.32659/tsj.v1i2.11

Phau, I., Quintal, V., \& Shanka, T. (2014). Examining a consumption values theory approach of young tourists toward destination choice intentions. International Journal of Culture, Tourism, and Hospitality Research, 8(2), 125-139. https://doi.org/10.1108/IJCTHR-12-2012-0090

Priyanto, R., Widiartono, \& Listyorini, S. (2016). Pengaruh Produk Wisata, Destination Image, dan Word of Mouth terhadap Keputusan Berkunjung (Studi Kasus pada Pengunjung Objek Wisata Goa Kreo Semarang). Jurnal Administrasi Bisnis, 5(1), 217-226.

Qu, H., Kim, L. H., \& Im, H. H. (2011). A model of destination branding: Integrating the concepts of the branding and destination image. Tourism Management, 32(3), 465-476. https://doi.org/10.1016/j.tourman.2010.03.014

Rahayu, S., \& Hendro, O. (2015). The Effect of Promotion, Service Quality, Brand Image on The Satisfaction of The Tourists Visiting The City Palembang and The Implication on Their Loyalty to The Visited Resorts. In Journal of Business and Economics.

Ramadhan, I., \& Susanta, H. (2016). Pengaruh Produk Wisata Dan Word Of Mouth Terhadap Keputusan Berkunjung (Studi Kasus pada Pengunjung Objek Wisata Pantai Klayar). Jurnal Ilmu Administrasi Bisnis, 5(4).

Rizki, M. A., \& Pangestuti, E. (2017). Pengaruh Terpaan Media Sosial Instagram Terhadap Citra Destinasi dan Dampaknya Pada Keputusan Berkunjung. Jurnal Administrasi Bisnis, 49(2), 157 164.

Safitasari, C., \& Maftukhah, I. (2017). Pengaruh Kualitas Layanan, Promosi dan Citra Destinasi terhadap Kepuasan melalui Keputusan Pengunjung. Management Analysis Journal, 6(3), 310319. https://doi.org/10.15294/maj.v6i3.17500

Sari, D. M. (2015). Partisipasi Masyarakat Dalam Mengembangkan Sarana Prasarana Kawasan Desa Wisata Borobudur. Ejural, 15(2), 133-140. https://doi.org/10.14710/mdl.15.2.2015.133-140

Setyaningsih, S., \& Murwatiningsih. (2017). Pengaruh Motivasi, Promosi Dan Citra Destinasi Pada Kepuasan Pengunjung Melalui Keputusan Pengunjung. Management Analysis Journal, 6(2).

Sudaryono. (2016). Manajemen Pemasaran Teori \& Implementasi. Yogyakarta: C.V ANDI OFFSET.

Surgawi, I. S. (2016). Analisis Pengaruh Produk Wisat, Persepsi Harga Dan Promosi Terhadap Keputusan Wisatawan Dalam Mengunjungi Objek Wisata (Studi pada Objek Wisata Puri Maerokoco Kota Semarang). Diponegoro Journal Of Management, 5, 1-10. Retrieved from http://ejournal-s1.undip.ac.id/index.php/management 
Valentino, I. (2019). Pengaruh Electronic Word Of Mouth Media Sosial Instagram, Atribut Produk Wisata Dan Citra Destinasi Terhadap Keputusan Berkunjung (Vol. 53). https://doi.org/10.1017/CBO9781107415324.004

Wu, H. C., Li, M. Y., \& Li, T. (2018). A Study of Experiential Quality, Experiential Value, Experiential Satisfaction, Theme Park Image, and Revisit Intention. In Journal of Hospitality and Tourism Research (Vol. 42). https://doi.org/10.1177/1096348014563396

Yoeti, O. A. (2013). Pemasaran Pariwisata. Bandung: CV Angkasa. 